\title{
Short communication: Cow- and herd-level prevalence of hypoglycemia in hyperketonemic postpartum dairy cows
}

\author{
J. Dubuc ${ }^{1}$ and S. Buczinski \\ Département de Sciences Cliniques, Faculté de Médecine Vétérinaire, Université de Montréal, St-Hyacinthe, QC J2S 2M2, Canada
}

\begin{abstract}
The objective of this study was to quantify the prevalence of hypoglycemia in hyperketonemic dairy cows during the early postpartum period. A prospective observational study was conducted in 100 dairy herds selected by convenience. Within all participating herds, 40 cows (or the entire herd if smaller than 40 cows) were enrolled in the study (total of 3,776 enrolled cows). Herds were visited every 2 wk by an animal health technician. Cows were bled from their coccygeal vessels once between 1 and $14 \mathrm{~d}$ in milk, and cow-side testing was performed for ketonemia and glycemia using a device validated in cattle (Precision Xtra, Abbott, Mississauga, ON, Canada). Hyperketonemia was defined as $\beta$-hydroxybutyrate $\geq 1.4 \mathrm{mmol} / \mathrm{L}$, and hypoglycemia was defined as glucose $\leq 2.2 \mathrm{mmol} / \mathrm{L}$. Descriptive statistics were computed at the cow and herd levels. The cow-level prevalence of hyperketonemia, hypoglycemia, and simultaneous hypoglycemia and hyperketonemia was $20.0 \%(757 / 3,776), 13.8 \%(642 / 3,776)$, and $6.2 \%$ $(235 / 3,776)$, respectively. Within the subset of hyperketonemic cows only, the prevalence of hypoglycemia was $31.0 \%$ (235/757). At the herd level, the median prevalence was $17.5 \%$ (minimum: $5.0 \%$, first quartile: $10.0 \%$, third quartile: $22.5 \%$, maximum: $77.5 \%$ ) for hyperketonemia, $15.0 \%$ (minimum: $5.0 \%$, first quartile: $12.5 \%$, third quartile: $20.0 \%$, maximum: $47.5 \%$ ) for hypoglycemia, and $7.5 \%$ (minimum: $2.5 \%$, first quartile: $5.0 \%$, third quartile: $12.5 \%$, maximum: $17.5 \%$ ) for simultaneous hypoglycemia and hyperketonemia. The herd-level median prevalence of hypoglycemia within the subset of hyperketonemic cows only was $30.6 \%$ (minimum: $2.5 \%$, first quartile: $20.0 \%$, third quartile: $39.1 \%$, maximum: $63.0 \%$ ). The results from this study show that the prevalence of simultaneous hyperketonemia and hypoglycemia is relatively low in the
\end{abstract}

Received August 31, 2017.

Accepted December 22, 2017.

${ }^{1}$ Corresponding author: jocelyn.dubuc@umontreal.ca overall early postpartum cow population but also that approximately one-third of hyperketonemic cows are hypoglycemic, which might represent an opportunity to improve their management on the farm.

Key words: hyperketonemia, hypoglycemia, prevalence, dairy cow

\section{Short Communication}

Hyperketonemia, defined as an elevated concentration of blood or serum BHB in dairy cows (Duffield et al., 2009), occurs mostly during the first weeks postpartum (McArt et al., 2012). It is a costly disease (McArt et al., 2015) because it increases the risk of additional disease and culling, reduces milk production, and reduces subsequent reproductive performance (Duffield et al., 2009; Ospina et al., 2010b; McArt et al., 2012). At the herd level, hyperketonemia is an important disease to monitor because its prevalence can vary greatly between herds and have significant negative effects (Ospina et al., 2010a; Suthar et al., 2013; Dubuc and Denis-Robichaud, 2017). For example, in a study of 126 commercial dairy herds conducted in Québec (Canada) in which 20 cows per herd were sampled once for BHB between 1 and 14 DIM, the herd-level prevalence of hyperketonemia varied between 4 and $75 \%$, with a median prevalence of 19\% (Dubuc and Denis-Robichaud, 2017).

Various treatment strategies for hyperketonemia have been tested in multiple studies with variable success (Gordon et al., 2013). The use of propylene glycol and cyanocobalamin has repeatedly been shown to improve the performance of hyperketonemic cows by increasing the cure rate or by improving the subsequent performance of the cows in milk production, reproduction, or disease (Rollin et al., 2010; McArt et al., 2011; Gordon et al., 2017). Interestingly, a recent study showed that hyperketonemic cows react to treatment differently depending on their glycemic status (Gordon et al., 2017). More specifically, the cure rate and subsequent performance of hyperketonemic cows was different between hypoglycemic (glycemia $\leq 2.2 \mathrm{mmol} / \mathrm{L}$ ) and normoglycemic (>2.2 mmol/L) cows (Gordon et al., 2017). 
These data suggest that monitoring both ketonemia and glycemia in early-postpartum cows could improve their management and treatment. Although testing simultaneously for ketonemia and glycemia is relatively easy to perform on farms when using validated cow-side tests (Iwersen et al., 2009; Wittrock et al., 2013; Mair et al., 2016), the prevalence of hypoglycemia and hyperketonemia in early-lactation cows remains unclear. Such information would clarify whether it would be of benefit to test both blood parameters. Therefore, the objective of the present study was to quantify the prevalence of hypoglycemia within the subset of hyperketonemic dairy cows during the early-postpartum period.

A total of 100 commercial dairy herds located within a 1-h drive of the bovine ambulatory clinic of the Université de Montréal (Faculté de Médecine Vétérinaire, St-Hyacinthe, QC, Canada) were recruited for this prospective observational study. Herd selection was based on convenience among the clients enrolled in a regular preventive medicine program at the bovine ambulatory clinic $(\mathrm{n}=135)$. Data collection was performed over a 1-yr period from November 2014 to October 2015. The sample size of 100 herds was targeted based on the following assumptions: an expected herd-level prevalence of hypoglycemia in hyperketonemic cows of $15 \%$, precision around the estimate of $5 \%$, and an $\alpha$-value of $5 \%$. Within every participating herd, 40 cows (or the entire herd if smaller than 40 cows) were systematically enrolled in the study during the data collection period. The sample size of 40 cows per herd was based on the following assumptions: expected cow-level prevalence of hypoglycemia in hyperketonemic cows of $15 \%$, $\alpha$-value of $5 \%$, and precision of estimate of $8 \%$.

Participating farms were visited every 2 wk by a veterinarian and an animal health technician. During farm visits, all cows between 1 and 14 DIM were bled from their coccygeal vessels to quantify ketonemia and glycemia using a cow-side device (Precision Xtra, Abbott, Mississauga, ON, Canada). For logistical reasons, cows were bled between 3 and $4 \mathrm{~h}$ after their first feeding of the day. The blood sample was collected in a 1-mL syringe and was immediately tested with the device that had been validated for use in cattle (Iwersen et al., 2009; Wittrock et al., 2013). The analytical sensitivity of the device for BHB was $0.1 \mathrm{mmol} / \mathrm{L}$, and its maximum value was $7.2 \mathrm{mmol} / \mathrm{L}$ (Iwersen et al., 2009). Hyperketonemia was defined as a blood BHB concentration of $\geq 1.4 \mathrm{mmol} / \mathrm{L}$ (Duffield et al., 2009). The analytical sensitivity and the maximum value of the device for glucose were 0.1 and $5.2 \mathrm{mmol} / \mathrm{L}$, respectively (Wittrock et al., 2013). Hypoglycemia was defined as a blood glucose value of $\leq 2.2 \mathrm{mmol} / \mathrm{L}$ based on response to insulin treatment (Gordon et al., 2017). Data collection procedures were approved by the animal care committee (14-Rech-1747) of the Université de Montréal (St-Hyacinthe, QC, Canada).

Statistical analyses were performed using SAS (version 9.4; SAS Institute Inc., Cary, NC). The experimental units of the study were the cow and the herd. Descriptive statistics were computed (PROC FREQ and PROC MEANS in SAS). The coefficient of correlation between ketonemia and glycemia values was also computed (PROC CORR in SAS). The cow-level prevalence of hyperketonemia (no. hyperketonemic/no. tested), hypoglycemia (no. hypoglycemic/no. tested), and simultaneous hypoglycemia and hyperketonemia (no. hyperketonemic and hypoglycemic/no. tested) was computed (PROC FREQ in SAS). The prevalence of hypoglycemia within the subset of hyperketonemic cows was also calculated (no. hyperketonemic and hypoglycemic/no. hyperketonemic). These calculations were performed for each individual herd as well as for the entire cow population (all cows pooled together). These data were also stratified by parity group (1, 2, 3 and more) and by DIM (1 to 14). In a second step, using the prevalence measures computed for each individual, herd-level descriptive statistics of the prevalence (minimum, maximum, quartiles, median) were computed (PROC MEANS and PROC FREQ in SAS). In other words, the within-herd prevalence of each herd was computed and ranked to determine the minimum and maximum values as well as quartiles and median values. Specifically, for the herd-level median prevalence of hypoglycemia among hyperketonemic cows only, it was calculated within each herd (no. hyperketonemic and hypoglycemic/no. hyperketonemic) and then ranked to determine the minimum and maximum values as well as quartiles and median values.

Data from 3,776 cows (100 herds) were collected in this study. The participating herds had a median size of 87 lactating cows (range: 31-371). The number of cows per herd enrolled in the study ranged from 31 to 40. The median DIM at sampling was 8 (range: $1-14$ ). At the cow level, the median values of ketonemia and glycemia were $0.8 \mathrm{mmol} / \mathrm{L}$ (range: $0.1-6.5$ ) and 3.0 $\mathrm{mmol} / \mathrm{L}$ (range: $0.5-5.2$ ), respectively. The coefficient of correlation between ketonemia and glycemia values was $-0.21(P<0.01)$. The prevalence of hypoglycemia among the subset of hyperketonemic cows only was $31.0 \%$ (235/757). Prevalence data stratified by parity group and by DIM are presented in Table 1 and Figure 1 , respectively. Herd-level prevalence data are also presented in Table 1. Glycemia frequency distributions for the overall study population as well as for the subset of hyperketonemic cows only are presented in Figure 2A. 


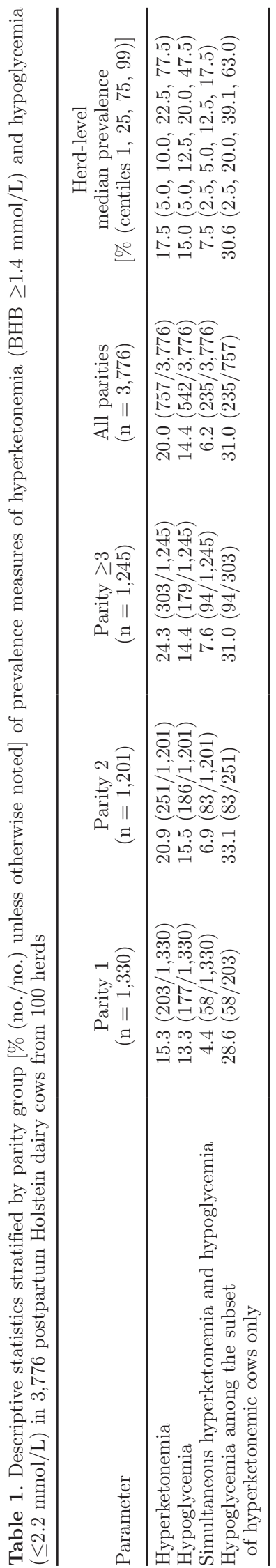

Ketonemia frequency distributions for the overall study population as well as for the subset of hypoglycemic cows only are presented in Figure 2B.

Although selection bias can occur in studies in which herds are selected by convenience, the prevalence of hyperketonemia in the present study was similar to that in other reports (Ospina et al., 2010a; Dubuc and Denis-Robichaud, 2017), which allows us to assume that our study population was relatively similar to the populations in those studies. In this context, our study results show that the prevalence of simultaneous hypoglycemia and hyperketonemia in the overall population of cows during the first 2 wk postpartum is generally low at $7.5 \%$ and that it can vary between 2.5 and $17.5 \%$. This represents a small proportion of cows within the first 2 wk postpartum. Therefore, performing a systematic surveillance for both hyperketonemia and hypoglycemia in these cows instead of doing surveillance only for hyperketonemia (as is the current practice for many herds) might not be logistically or economically interesting, especially when there are very few data to support taking action in cows that are hypoglycemic only. Further research should explore the economics of this testing strategy.

To maximize the identification of cows affected by both hyperketonemia and hypoglycemia, a more intuitive surveillance strategy could be to perform a serial interpretation of multiple test results (Dohoo et al., 2003). In other words, systematic surveillance of hyperketonemia could be implemented on a farm, and glycemia would be tested for only once a hyperketonemic cow had been found. In that context, it appears that roughly one-third of the hyperketonemic animals would also be hypoglycemic at the time of sampling. If relevant, a specific treatment such as insulin could then be used (in countries that allow it) in those cows to improve the hyperketonemia cure rate and the subsequent cow performance (Gordon et al., 2017). However, further research should explore the usefulness of this testing and treatment hypothesis.

Our results showed that roughly one-third of hyperketonemic cows are simultaneously hypoglycemic when a systematic surveillance program is performed during the first 2 wk postpartum. It remains unclear at this point whether this proportion is similar in the population of sick cows that are examined by veterinarians in their individual daily medical work. Early-postpartum cows that are shown to veterinarians in such context are sick (e.g., metritis, mastitis, displaced abomasum) and are likely not eating well. It could be speculated that a greater proportion of hypoglycemia would be found among hyperketonemic cows in this population, but that remains to be investigated. The present study results should be interpreted considering the context 
of data collection (systematic postpartum hyperketonemia surveillance program vs. sick cow cases that are hyperketonemic). They should also be interpreted knowing that the glucose threshold used to classify cows as hypoglycemic $(\leq 2.2 \mathrm{mmol} / \mathrm{L})$ is based on the results reported by a recent study showing that in hyperketonemic cows, the response to hyperketonemia treatment is largely different between cows that are hypoglycemic and cows that are normoglycemic (Gordon et al., 2017). In this latter study, the reported glucose threshold was found a posteriori (during statistical analyses) to optimally discriminate between the treatment efficacy within 2 subpopulations of cows. It was not the intent of the present study to determine whether the optimal glucose threshold is $\leq 2.2 \mathrm{mmol} / \mathrm{L}$. The main goal of the present study was to describe the prevalence of this condition in a large sample size of cows and herds to provide insights about its frequency of occurrence. Therefore, future studies should re-explore and confirm that the optimal glucose threshold in this context remains $\leq 2.2 \mathrm{mmol} / \mathrm{L}$.

\section{- Hyperketonemia}

$\otimes$ Simultaneous hyperketonemia and hypoglycemia
A weakness of the present study is that ketonemia and glycemia were monitored only once for each cow within the first 14 DIM. Unfortunately, it was not logistically feasible to sample differently considering that almost 40 cows from 100 herds were visited every $14 \mathrm{~d}$ during data collection. It should also be kept in mind that prevalence, not incidence, of disease was computed. Thus, the reported prevalence can only be inferred to the study sampling period (first 2 wk postpartum). Sampling at an earlier or later stage of lactation might lead to different prevalence results. The study results should also be interpreted knowing that cows were bled 3 to $4 \mathrm{~h}$ after their first meal of the day. This is likely to cause a postprandial confounding effect on glycemia and ketonemia values, which could alter the investigated prevalence of hyperketonemia and hypoglycemia. Future studies designed for sampling cows more frequently or on a daily basis should explore the effect of this potential confounding factor. Unfortunately, it was not possible to explore it because of the present study design.

\section{口Hypoglycemia \\ 웅 Hypoglycemia within the subset of hyperketonemic cows}

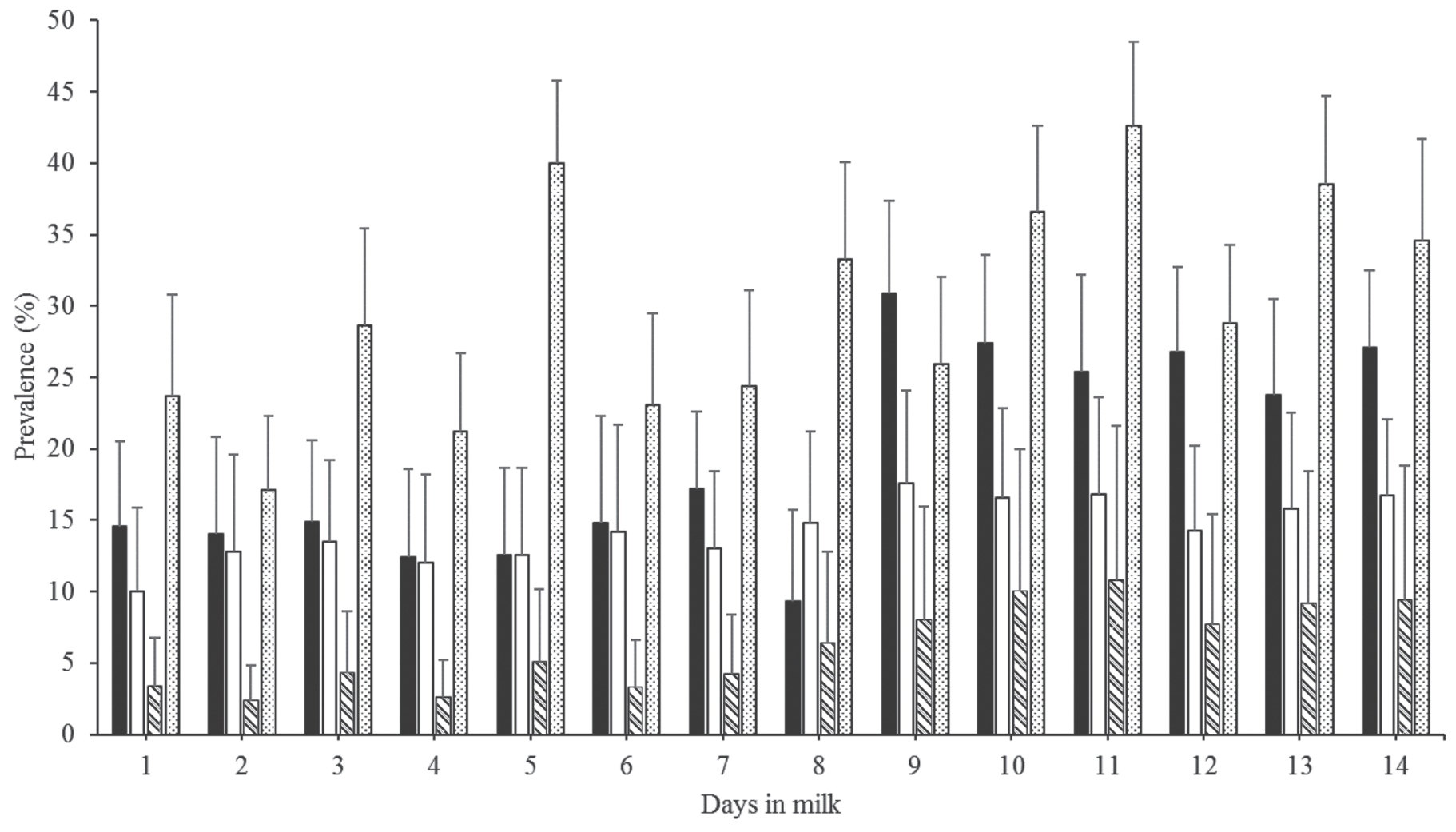

Figure 1. Prevalence $( \pm \mathrm{SD})$ distribution of hyperketonemia $(\mathrm{BHB} \geq 1.4 \mathrm{mmol} / \mathrm{L})$ and hypoglycemia $(\leq 2.2 \mathrm{mmol} / \mathrm{L})$ stratified by DIM in a population of 3,776 cows from 100 herds enrolled in an observational study. Distributions are presented as the overall prevalence of hyperketonemia, the overall prevalence of hypoglycemia, the overall prevalence of simultaneous hyperketonemia and hypoglycemia, and the prevalence of hypoglycemia within the subset of hyperketonemic cows only. 
Finally, it should be kept in mind that the present study results were obtained from dairy herds with a median size of 87 lactating cows (range: $31-371$ ), which is common in Québec (Canada) but might be different from other locations around the world. Inference of the present study results should account for this specific

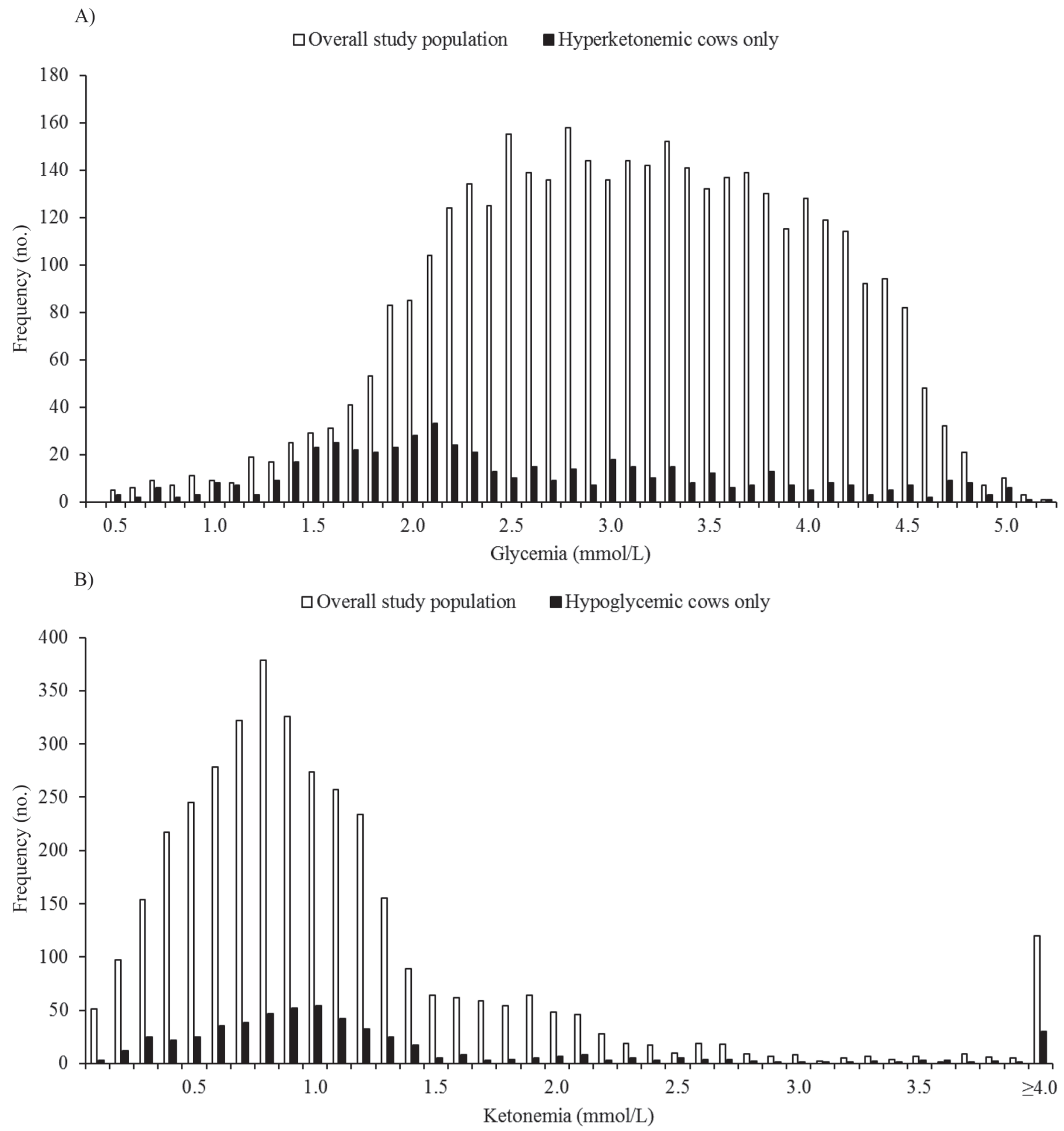

Figure 2. Glycemia and ketonemia frequency distributions in a population of 3.776 cows from 100 dairy herds enrolled in an observational study. (A) Glycemia distribution for the overall study population and for the hyperketonemic (BHB $\geq 1.4$ mmol/L) cows only. (B) Ketonemia distribution for the overall study population and for the hypoglycemic $(\leq 2.2 \mathrm{mmol} / \mathrm{L})$ cows only. 
context, as larger herds along with the usual management systems associated with herd size might yield different hyperketonemia and hypoglycemia dynamics. Future studies should explore this aspect.

Overall, the results of the present study suggest that the prevalence of cows affected simultaneously by hypoglycemia and hyperketonemia is relatively low in the overall early-postpartum cow population but also that hypoglycemia affects roughly one-third of hyperketonemic cows. Future research should investigate optimal strategies to manage this subpopulation of fresh cows.

\section{ACKNOWLEDGMENTS}

The data used in the current study were retrieved from a research project funded by Le Ministère de l'Agriculture, des Pêcheries et de l'Alimentation du Québec (Québec, QC, Canada) Programme Innov'Action, with a research grant attributed to Jocelyn Dubuc (IA113014). Additional funding was also provided by the Zoetis clinical research fund of the bovine ambulatory clinic of the Université de Montréal (St-Hyacinthe, QC, Canada). The authors acknowledge the technical work of Jean-Philippe Pelletier (Université de Montréal) during this project and all of the dairy farmers who agreed to participate in this study.

\section{REFERENCES}

Dohoo, I., W. Martin, and H. Stryhn. 2003. Veterinary Epidemiologic Research. 1st ed. VER Inc., Charlottetown, PE, Canada.

Dubuc, J., and J. Denis-Robichaud. 2017. A dairy herd-level study of postpartum diseases and their association with reproductive performance and culling. J. Dairy Sci. 100:3068-3078.

Duffield, T. F., K. D. Lissemore, B. W. McBride, and K. E. Leslie. 2009. Impact of hyperketonemia in early lactation dairy cows on health and production. J. Dairy Sci. 92:571-580.
Gordon, J. L., T. F. Duffield, T. H. Herdt, D. F. Kelton, L. Neuder, and S. J. LeBlanc. 2017. Effects of a combination butaphosphan and cyanocobalamin product and insulin on ketosis resolution and milk production. J. Dairy Sci. 100:2954-2966.

Gordon, J. L., S. J. LeBlanc, and T. F. Duffield. 2013. Ketosis treatment in lactating dairy cattle. Vet. Clin. North Am. Food Anim. Pract. 29:433-445.

Iwersen, M., U. Falkenberg, R. Voigtsberger, D. Forderung, and W. Heuwieser. 2009. Evaluation of an electronic cowside test to detect subclinical ketosis in dairy cows. J. Dairy Sci. 92:2618-2624.

Mair, B., M. Drillich, D. Klein-Jöbstl, P. Kanz, S. Borchardt, L. Meyer, I. Schwendenwein, and M. Iwersen. 2016. Glucose concentration in capillary blood of dairy cows obtained by a minimally invasive lancet technique and determined with three different hand-held devices. BMC Vet. Res. 12:34.

McArt, J. A. A., D. V. Nydam, and G. R. Oetzel. 2012. Epidemiology of subclinical ketosis in early lactation dairy cattle. J. Dairy Sci. 95:5056-5066.

McArt, J. A. A., D. V. Nydam, P. A. Ospina, and G. R. Oetzel. 2011. A field trial on the effect of propylene glycol on milk yield and resolution of ketosis in fresh cows diagnosed with subclinical ketosis. J. Dairy Sci. 94:6011-6020.

McArt, J. A. A., D. V. Nydam, and M. W. Overton. 2015. Hyperketonemia in early lactation dairy cattle: A deterministic estimate of component and total cost per case. J. Dairy Sci. 98:2043-2054.

Ospina, P. A., D. V. Nydam, T. Stokol, and T. R. Overton. 2010a. Association between the proportion of sampled transition cows with increased nonesterified fatty acids and $\beta$-hydroxybutyrate and disease incidence, pregnancy rate, and milk production at the herd level. J. Dairy Sci. 93:3595-3601.

Ospina, P. A., D. V. Nydam, T. Stokol, and T. R. Overton. 2010b. Associations of elevated nonesterified fatty acids and $\beta$-hydroxybutyrate concentrations with early lactation reproductive performance and milk production in transition dairy cattle in the northeastern United States. J. Dairy Sci. 93:1596-1603.

Rollin, E., R. D. Berghaus, P. Rapnicki, S. M. Godden, and M. W. Overton. 2010. The effect of injectable butaphosphan and cyanocobalamin on postpartum serum $\beta$-hydroxybutyrate, calcium, and phosphorus concentrations in dairy cattle. J. Dairy Sci. 93:978 987.

Suthar, V. S., J. Canelas-Raposo, A. Deniz, and W. Heuwieser. 2013. Prevalence of subclinical ketosis and relationships with postpartum diseases in European dairy cows. J. Dairy Sci. 96:2925-2938.

Wittrock, J. A. M., T. F. Duffield, and S. J. LeBlanc. 2013. Validation of a point-of-care glucometer for use in dairy cows. J. Dairy Sci. 96:4514-4518. 